\title{
TRANSPORTATION, LOGISTICS AND REGIONAL DEVELOPMENT IN COVID-19 ERA: MODELLING SECTORAL SHOCKS CAUSED BY POLICY AND SAFETY MEASURES
}

\author{
*Astra Auziņa-Emsin̨a, Velga Ozoliṇa \\ Riga Technical University, Latvia \\ *Corresponding author's email: astra.auzina-emsina@rtu.lv
}

\begin{abstract}
COVID-19 policy and measures have caused both negative and positive challenges for the transport sector. The aim of the research is to model an impact of shocks that transport and logistics encounter during the COVID-19 era on the economy and regional development. A comparative-static approach that involves an input-output model with additional regional modelling block and scenarios are applied. Two scenarios are estimated for Latvia's economy: firstly, extremely dramatic decline in demand on air transport services by $90 \%$; secondly, unexpected increase in demand for postal and courier services that doubled output. The results of the first scenario argue that the service sector is influenced more than manufacturing due to air transport collapse -rental and leasing services $(-11.6 \%)$, employment services $(-9.7 \%)$, other transport services $(-7.0 \%)$, impact on manufacturing is relatively minor and only on certain branches. The results of the second scenario on doubled output in postal and courier services argue that there is a positive impact, but the scale is relatively low, the most affected industries are manufacturing (of paper products (increase by $1.7 \%$ ), rubber and plastic goods $(1.6 \%)$ ). The findings confirm that the urban areas due to higher economic activity and larger service sector are more affected to the modelled shocks both negative and positive. The rural areas are relatively less negatively affected during the crisis, but at the same time, during the recovery (for example, in the post-COVID era) it may lead to weaker economic activity and the rural areas will continue to lag behind urban areas.
\end{abstract}

Key words: modelling, COVID-19 shocks, regional development, rural areas, transport, logistics, input-output analysis.

\section{Introduction}

Economic impact of COVID-19 has received a lot of research attention. A number of recent studies have examined various aspects of COVID-19 era restrictions, limitations, policies, direct and side effects and various impacts, including economic impacts. Considerable research attention has been directed towards COVID-19 impact on supplychains, transport, logistics, delivery organisation and management. The recent findings (Gray, 2020) outline that the pandemic and the measures to address the pandemic have created significant new challenges for transportation system. These challenges include both negative (restrictions, risks, additional costs, lockdowns etc.) and positive (unexpected booming of niche industries, as courier services, online services, take-away food deliveries, etc.) activities.

It is generally agreed that COVID-19 is a new phenomenon that is under ongoing studies. Kim (Kim, 2021) outlines that the knowledge of COVID-19 impacts on transportation and society continues to evolve and progress, and at the same time he concludes that a wide range of different theoretical approaches and analytical techniques, methods, styles of research, even new type of data sources (as mobile phone location data) can be used in interdisciplinary research.

Transport and logistics sectors have been influenced differently, not only by policy measures but also by customers' unpredictable behaviour. Even studies in relatively stable transport sectors as public transportation (Tirachini \& Cats, 2020) outline great challenge for contemporary public transportation worldwide, resulting from an unprecedented decline in demand and revenue. The study (Wielechowski, Czech, \& Grzęda, 2020) assesses the changes in mobility in public transport in one country (Poland) caused by the COVID-19 pandemic from the country and regional perspective and the findings reveal a negative but insignificant relationship between human mobility changes in public transport and the number of new confirmed COVID-19 cases; however, the strength and statistical significance of the correlation significantly varies regionally.

Regional perspective is an important issue to take into account as development differs in urban and rural areas. The results of the study (Wen, Sheng, \& Sharp, 2021) on the impact of COVID-19 on changes in community mobility and variation in transport indicates that regional heterogeneity in the variation of public transport use was evident in New Zealand. Of all the transport modes, air transportation had faced extremely severe limitations, flight restrictions and other policy measures. The studies (Sobieralski, 2020) argue that recovery following uncertainty shocks is estimated to take between four and six years. Air transportation in various regions has undergone various impacts. The authors (Sun, Wandelt, \& Zhang, 2020) outline that Europe has undergone probably the most significant changes regarding domestic flight network connectivity, while the United States suffered less severely and China is recovering. The authors (Sun et al., 2020) conclude that the evolutionary dynamics 
of domestic airport networks are strongly correlated with the COVID-19 situation in each country.

However, the recovery highly depends on customers' decisions and behaviour, especially in air transportation. Several researchers (Monmousseau et al., 2020) analysed the effect of the travel restriction measures caused by COVID-19 pandemic from a passenger perspective on USA air transportation system. Four passenger-centric metrics (empathy score, sentiment gap, quality response, quantity response) were proposed and extracted from passengergenerated data as these data could be gathered earlier than official flight data (Monmousseau et al., 2020).

Passenger transportation is closely linked with tourism industry. As cruise tourism was paused as a result of the COVID-19, the studies offer innovative and adaptive solutions to new reality. For example, Renaud (Renaud, 2020) argues to promote the development of a niche cruise tourism industry with small ships; however, he stresses that mass cruise tourism industry will do everything in its power to regain its hegemonic position. Tourists expectations have huge impact on decisions and spending, for example, the study on impacts of COVID-19 crisis over the tourism expectations in Azores Archipelago (Couto et al., 2020), where tourism is a strategic sector for the regional economy and growth, argues that the paradigm of persons attitudes in choosing the time and form of vacation has substantially changed. Regarding tourism industry, probably the only certainty for this industry is that nothing will be like it was in the preCOVID-19 era (Renaud, 2020). This idea is shared by many other studies.

The negative aspects are more examined and assessed rather than positive aspects regarding conditions and restrictions in COVID-19 era. The study (Abel \& Gietel-Basten, 2020) outlines that tightening of international borders during and after COVID-19 pandemic has a significant impact on international labour force migration and international remittance flows. In result, the authors (Abel \& GietelBasten, 2020) stress that negative health, economic, social or political changes for labour migrants in one territory will have profound consequences far across the world. The results of Italian case (Giammetti et al., 2020) suggest that by stopping the production process of many key sectors, the lockdown has led to a drop in input and output that, in turn, has generated a lock of about $52 \%$ of total circulating value added, $30 \%$ of which has been locked within indirect value chains. Some sectors and economic agents in the economy even gain, for example, Gray (Gray, 2020) has found that the reduced demand for transportation services in most other sectors of the economy reduce transportation costs and increase transportation availability for most agricultural supply chain.
Studies examine the further development in postCOVID era. The study (Collier \& Mayer, 2020) examines the promotion of small and mediumsized enterprises post-COVID in the provinces of the United Kingdom focusing on how reforming one certain system (in this case, financial system) promotes regional development. Sustainable regional development ensures urban-rural income convergence reducing the income gap and income inequality in rural areas compared with urban areas (cities and towns) (Auzina-Emsina \& Ozolina, 2019) that are mighty motivators for youngest generation to stay in rural areas in developed countries. The study on 65 countries (Young, 2013) argues that one out of every four or five individuals raised in rural areas moves to urban areas as a young adult in order to increase net income and actually earns more than rural population that has not migrated. Regional development is closely linked with migration both national and international.

COVID-19 pandemic impact on various aspects has been investigated by a wide range of methods. Input-output approach (alone or incorporated in models) is used in numerous researches. The recent study (Bonet-Morón et al., 2020) uses input-output model and scenarios analysis, the results indicate that depending on the scenario considered, accommodation and food services, real estate, administrative services, construction and trade are the most affected sectors. The study of (Giammetti et al., 2020) employ techniques of complex networks analysis and inputoutput traditional tools, the study identifies key affected sectors. Complex study (Lenzen et al., 2020) on global socio-economic losses and environmental gains from the coronavirus pandemic uses a global multi-regional macro-economic model that is capable to capture direct and indirect spill-over effects social, economic and environmental effects. New circumstances and new conditions introduce new and innovative data use. Mobile positioning data provided at a high spatial granularity (up to NUTS3) are used analysing the impact of COVID-19 confinement on mobility in Europe (Santamaria et al., 2020).

Researches devoted to modelling regional development and impact on certain regions in countries reveal that policy is a key element. The study on Italian regions (Arbolino \& Caro, 2020) argues that the COVID-19 shock is producing the major adverse effects on regional labour markets in certain regions (in the South Italy) and on female occupations. The authors stress the impact of the European Union (EU) funded projects that should be addressed to reduce the vulnerability of labour markets and occupations that show low resistance to shocks and weak recoverability (Arbolino \& Caro, 2020). The literature review indicates that regional development deserves more research attention. 
The aim of this research is to model an impact of shocks that transport and logistics encounter during the COVID-19 era on the national economy and regional economic activity. For this purpose a comparative-static approach that involves an inputoutput model with additional regional modelling block and scenarios, is applied. The research involves the analysis and detection of current trends in the EU regarding transport sector, input-output model building, elaboration of scenarios assumptions, and modelling the results. The literature review and findings suggest that sophisticated systematic and modelling tools give accurate and valuable results.

\section{Materials and Methods}

In the research, the high level of sectoral disaggregation of the economy is used that is based on the classification of economic activity (NACE) Rev.2. that subdivides the economic activity into 64 industries. Transport is classified according to $\mathrm{H}$ industry that consists of: Land transport and transport via pipelines (NACE code H49), water transport (H50), air transport (51), warehousing and support activities for transportation (H52), and postal and courier activities (H52). As a result, the elaborated input-output model computes the results for 64 economic activities.

In order to reveal various aspects and observe the phenomena from different perspectives, the regional development is analysed and modelled by two approaches. Firstly, regional development is analysed according to NUTS3 level. Latvia is subdivided into six regions according to NUTS 3 level: Riga, Pieriga, Kurzeme, Zemgale, Vidzeme, and Latgale. Secondly, the urban-rural typology of Eurostat (Eurostat, 2018) is applied that classify regions into: predominantly urban regions, intermediate regions, predominantly rural regions.
The research is based on the EU data and Eurostat classification. The research period is 2015-2020 (or till latest statistics available). The research uses the latest available symmetric input-output (productto-product) table of 2015 that is actually a set of tables, including domestic input-output and import input-output tables. According to Eurostat, national statistical offices can prepare symmetric input-output tables in product-by-product or in industry-byindustry approach. The majority of the EU countries prefer the product-to-product approach for symmetric input-output tables. The set of input-output tables offers valuable information for static analysis, but it is impossible to analyse dynamics or perform comparative-static analysis.

The impact of sectoral shocks is modelled as the scenario analysis applying input-output model. In this research, the impact and the so-called what-if scenarios are evaluated in short term and medium term hence technological coefficients are constant. The what-if scenarios allow to estimate the quantitative effect of a certain (or given) change in the economy. The elaborated input-output model includes the basic identities that ensure the equilibrium in the economy and additional regional development modelling block.

The modelling process includes several stages: firstly, the direct and indirect impact modelling using main input-output model, obtaining results for 64 economic activities. Secondly, the values are aggregated into 10 major NACE groups (NACE codes: A, B-E (except F), E, F, G-J, K, L, M-N, O-Q, $\mathrm{R}-\mathrm{U}$ ) and used for regional development modelling block - both, firstly, compute the sectoral economic activity in six regions, sum the results and obtain the certain region's totals by bottom-up approach; secondly, compute the sectoral economic activity in predominantly urban regions, intermediate regions,

Table 1

Transport dynamics in the EU and Latvia in 2016-2019 (value added, chain linked volumes, index 2015=100)

\begin{tabular}{|l|c|c|c|c|c|c|c|c|}
\hline \multirow{2}{*}{\multicolumn{1}{|c}{ Industry/Time }} & \multicolumn{3}{c|}{ European Union - 27 countries } & \multicolumn{4}{c|}{ Latvia } \\
\cline { 2 - 10 } & 2016 & 2017 & 2018 & 2019 & 2016 & 2017 & 2018 & 2019 \\
\hline Total - all NACE activities & 101.9 & 104.8 & 107.0 & 108.6 & 101.8 & 105.1 & 108.7 & 111.3 \\
\hline Transportation and storage & 100.8 & 105.1 & 108.0 & 110.2 & 101.7 & 108.3 & 112.6 & 109.6 \\
\hline Land transport and transport via pipelines & 100.3 & 104.4 & 106.8 & $:$ & 102.3 & 110.9 & 106.1 & $:$ \\
\hline Water transport & 104 & 107.4 & 110.2 & $:$ & 95.0 & 91.7 & 85.5 & $:$ \\
\hline Air transport* & 103.2 & 114.7 & 127.1 & $:$ & 123.9 & 153.9 & 185.3 & $:$ \\
\hline $\begin{array}{l}\text { Warehousing and support activities for } \\
\text { transportation }\end{array}$ & 101.3 & 105.9 & 108.9 & $:$ & 94.8 & 95.5 & 97.9 & $:$ \\
\hline Postal and courier activities & 97.8 & 97.3 & 95.7 & $:$ & 95.3 & 98.9 & 108.6 & $:$ \\
\hline
\end{tabular}

: no data available; * For Latvia, the data on output dynamics are given due to classification updates and observable breaks in series. 
and predominantly rural regions, sum the results and obtain the certain area's totals by bottom-up approach.

The research data analysis covers the whole EU, but modelling is executed on the case of one EU country - Latvia. The method and the scenarios are applicable to the EU countries facing similar research questions.

\section{Results and Discussion}

Transport sector has experienced a stable and industry-wide development in 2015-2019 in the EU, as well as in Latvia. According to the Eurostat data, the transportation and storage has grown faster than the total EU economy. In recent years air transport has been influenced by various factors that resulted in dynamics of chain linked volumes both in the EU and Latvia with extremely high index values (see Table 1).

The COVID-19 conditions and policy measures that were introduced in early 2020 significantly shocked the transport sector, especially the severe limitations were applied to air transport. It resulted in output decline by $90 \%$ or more if compared with a year before. According to the Eurostat (Eurostat, 2020) data, the number of passengers carried decreased by more than $91 \%$ in 20 EU countries in the second quarter 2020 compared with second semester of 2019: the largest decreases in numbers of passengers were observed in Spain ( $-99 \%)$, Germany (-97\%), France $(-97 \%)$. All EU airports registered a dramatic fall in the number of passengers handled. Due to the COVID-19 related strict trade limitations, introduction of severe safety restrictions and activities, even lockdown of cafes, restaurants, etc. in many EU countries that resulted in e-commerce boom and increase of postal and courier delivery services in all EU countries.

However, the pattern of recent development was significantly impacted by policy measures, restrictions regarding certain sectors in the economy in all EU countries. The most severe restrictions and limitations were applied to air transport, hotels and recreations, restaurants, cafes, public events, etc. sectors. Many governments introduced the support and compensations mechanisms and additional funds. However, it is valuable to estimate the impact on the economy if these support actions have not been introduced. Hence, in the research, the shock scenario analysis is applied.

To model the impact of sectoral shocks caused by policy and safety measures in COVID-19 era, evaluating the macroeconomic, sectoral and regional perspective, two comparative-static scenarios are estimated taking into account the above-detected trends and assumptions (based on data analysed) in Latvia's economy:

1) air transport services (NACE code H51) experience a dramatic demand decrease by $90 \%$ (due to policy measures and flight restrictions), it is assumed that the general consumption pattern and routine is constant as it is an unexpected shortterm shock with unknown length of impact. The society believes that it will soon be over. The other indicators (as regional allocation of economic activity by NUTS 3 level and economic activity by urbanisation of area, etc.) are unchanged - ceteris paribus. This scenario involves computing the impact on shocked industry, computing direct and indirect impact on other industries (64 industries), on the basis of computed sectoral development results, the impact on six regions (NUTS 3 level) is computed, how it has affected the economic activity in cities, towns, suburbs, and rural areas. The scenario illustrates the impact of collapse of one industry on the rest of the economy in different perspectives without government compensation mechanisms or support programs;

2) Output of postal and courier services (NACE code H53) doubled due to the government restrictions and safety measures regarding shops, markets, etc. and households and business tend to maintain the consumption pattern as used, consume the goods (including food and beverages, materials, electronics, etc.) but buy more goods online (or use other distance shopping options) with delivery. The courier services and pickup point services experience overload. However, it is an unexpected short-term shock with unknown length of impact for both economic actors - households and courier and postal service companies. At the same time, the general belief is that it soon will be over. The other indicators (as regional allocation of economic activity by NUTS 3 level and economic activity by urbanisation of area, etc.) are unchanged - ceteris paribus. This scenario also involves computing the impact on shocked industry, computing direct and indirect impact on other industries (64 industries) and the impact on six regions (NUTS 3 level), and how it has affected the economic activity in cities, towns, suburbs, and rural areas. The scenario demonstrates the impact of demand increase observed in one industry on the rest of the economy in different perspectives without additional government compensation mechanisms or support programs. The aim is to estimate the impact of relatively forced decisions (caused by restrictions allowing to buy online but not in shop) made by economic agents on the economy.

The selected and modelled above-given scenarios illustrate that in any economic crisis there are industries that experience dramatic decline and at the same time there might be specific industries or niches that have hard times to manage the overload and overdemand situation. And both extreme cases can be 
Modelling results of the first scenario representing sectoral output change (\%)

\begin{tabular}{|c|l|c|}
\hline NACE/CPA CODE & \multicolumn{1}{|c|}{ Product or service } & Impact \\
\hline H51 & Air transport services & $-67.3 \%$ \\
\hline N77 & Rental and leasing services & $-11.6 \%$ \\
\hline N78 & Employment services & $-9.7 \%$ \\
\hline C30 & Other transport equipment & $-7.0 \%$ \\
\hline H52 & Warehousing and support services for transportation & $-6.8 \%$ \\
\hline C22 & Rubber and plastic products & $-5.4 \%$ \\
\hline N79 & Travel agency, tour operator and other reservation services and related services & $-5.3 \%$ \\
\hline C20 & Chemicals and chemical products & $-3.3 \%$ \\
\hline J62_63 & Computer programming, consultancy and related services; Information services & $-3.0 \%$ \\
\hline C24 & Basic metals & $-2.5 \%$ \\
\hline
\end{tabular}

observed even in one economic sector - in transport services (according to NACE $\mathrm{H}$ industry) all at once. COVID-19 caused conditions allowing that long-time unexpected shock could come about, which is even relatively unusual to economic modelling community and scenario analysis.

The results of the first scenario estimated by the input-output model claim that the impact on the economy is clearly observable and noticeable. The total final consumption expenditure of households decreases by $1.3 \%$, the overall national economic decline is estimated by $-1.1 \%$.

Air transport services are interlinked directly and indirectly with many domestic industries as well as consume large amount of imported goods, only the major impacts are analysed in detail. Table 2 shows the modelled full (direct and indirect) impact results of product output changes that are larger than $-2.5 \%$ (output of products with the impact below 2.5\% are not included in the Table 2) and represents ten industries that are the most affected. If private persons travel only due to significant reasons (as re-emigration flights home, re-union of family, death of relative, etc.), due to government restrictions results in collapse of the industry (output decline by $-67.3 \%$ ); at this point, it is worth to stress that this scenario assumes that commercial cargo and human aid, etc. flights are unshocked.

The modelling results show that service sector is influenced more than manufacturing - for example, rental and leasing services $(-11.6 \%)$, employment services $(-9.7 \%)$, other transport services $(-7.0 \%)$, warehouse, etc. services $(-6.8 \%)$, travel agencies $(-5.3 \%)$, as compared to manufacturing of rubber and plastic products $(-5.4 \%)$, Chemicals and chemical products $(-3.3 \%)$, basic metals $(-2.5 \%)$.

Table 3

Modelling results of the second scenario representing sectoral output change (\%)

\begin{tabular}{|c|l|c|}
\hline NACE/CPA CODE & \multicolumn{1}{|c|}{ Product or service } & Impact \\
\hline C17 & Paper and paper products & $1.7 \%$ \\
\hline C22 & Rubber and plastic products & $1.6 \%$ \\
\hline N77 & Rental and leasing services & $0.5 \%$ \\
\hline H52 & Warehousing and support services for transportation & $0.5 \%$ \\
\hline C20 & Chemicals and chemical products & $0.4 \%$ \\
\hline N80_82 & $\begin{array}{l}\text { Security and investigation services; services to buildings and landscape; office } \\
\text { administrative, office support and other business support services }\end{array}$ & $0.4 \%$ \\
\hline J58 & Publishing services & $0.4 \%$ \\
\hline H51 & Air transport services & $0.4 \%$ \\
\hline M69_70 & $\begin{array}{l}\text { Legal and accounting services; services of head offices; management consultancy } \\
\text { services }\end{array}$ & $0.4 \%$ \\
\hline J62_63 & Computer programming, consultancy and related services; Information services & $0.3 \%$ \\
\hline
\end{tabular}


Modelling results of the two scenarios representing regional output change (\%)

\begin{tabular}{|l|c|c|c|c|c|c|c|}
\hline Scenarios/NUTS3 & TOTAL & Riga & Pieriga & Vidzeme & Kurzeme & Latgale & Zemgale \\
\hline First scenario & $-1.14 \%$ & $-1.29 \%$ & $-1.14 \%$ & $-0.85 \%$ & $-0.97 \%$ & $-0.86 \%$ & $-0.86 \%$ \\
\hline Second scenario & $0.48 \%$ & $0.51 \%$ & $0.53 \%$ & $0.35 \%$ & $0.46 \%$ & $0.41 \%$ & $0.37 \%$ \\
\hline
\end{tabular}

Table 5

Modelling results of the two scenarios representing output change in territories regarding level of urbanisation (\%)

\begin{tabular}{|l|c|c|c|c|}
\hline \multicolumn{1}{|c|}{ Scenarios/Territory } & TOTAL & $\begin{array}{c}\text { Predominantly urban } \\
\text { regions }\end{array}$ & $\begin{array}{c}\text { Intermediate } \\
\text { regions }\end{array}$ & Predominantly rural regions \\
\hline First scenario & $-1.14 \%$ & $-1.29 \%$ & $-1.03 \%$ & $-0.85 \%$ \\
\hline Second scenario & $0.48 \%$ & $0.51 \%$ & $0.48 \%$ & $0.36 \%$ \\
\hline
\end{tabular}

The results of the second scenario estimated by the input-output model claim that impact on the economy is noticeable but with lower impact level as in the first scenario as the analysed industry (postal and courier services) is supplementary service activity, and it has a smaller share in the economy. As a result, if postal and courier services experience a doubled demand, the total economic activity increases by $0.5 \%$. As domestically produced and imported goods can be delivered, the impacts on national industries are various. Table 3 shows the modelled full (direct and indirect) impact results of product output change that are larger than $0.3 \%$ (output of products with the impact below $0.3 \%$ are not included in Table 3) and represents ten industries that are the most affected.

The postal and courier services consumes relative low share of intermediate goods of other domestic industries and have relatively high proportion of labour costs in the costs structure. And, in this case, the modelling results show that even extremely positive impact on this industry doubling the demand does not significantly affect the rest of the economy. No doubt, there is a positive impact, but the scale is relatively low. The results claim that the most affected industries are manufacturing of paper products (output increase by $1.7 \%)$, rubber and plastic goods (1.6\%) and supportive services industries as rental and leasing services $(0.5 \%)$, warehousing and support services for transportation $(0.5 \%)$. Other industries have an impact that is lower than $0.4 \%$.

Within the modelling scenarios it is worth to stress the specific of one industry coke and refined petroleum products (C19) due to the fact that it is almost completely import based industry and any, even minor, changes generate unreasonably high changes but in absolute figures the change is minor.
Regional economic activity depends on various factors (as availability of resources, infrastructure, skilled labour force, production traditions and history, etc.), it quite varies among different regions; and hence economic shocks affect the regions differently. The scenarios modelling includes the regional modelling block that uses sectoral data and regional structure according to NUTS 3 for six regions and computes the results using bottom-up approach. The modelling results claim that the drastic demand fall for the air transport by $90 \%$ has a larger impact on the economic performance in the capital city (Riga) and near municipalities. Table 4 is a summary of regional economic effect caused by the scenarios. The data provide convincing evidence that dramatic economic shocks have larger impact both positive and negative on Riga region and Pieriga region, and relatively lesser impact on Kurzeme, Vidzeme, Zemgale, and Latgale region.

The results provide convincing evidence that urban areas are the most affected if as dramatic shocks as modelled take place (Table 5). In the case of the first scenario, when air transport demand falls by $90 \%$ the economic activity in the predominantly urban regions falls by $1.3 \%$ (when national-level decline is by $1.1 \%$ ); meanwhile, the economy in predominantly rural regions shrinks only by $0.9 \%$. The results of the second scenario of postal and courier services are consistent with previous results showing that predominantly urban regions are exposed more to economic shocks.

The general picture emerging from the analysis and modelling is that the urban regions due to higher economic activity and larger service sector are more affected to shocks both negative and positive that transport sector encounters. The rural areas are relatively less negatively affected during the crisis, 
but at the same time, during economic recovery or some short-term economic boom (for example, in the post-COVID era) may lead to weaker and slower economic activity and the lagging behind urban areas will remain.

\section{Conclusions}

Government policy and safety measures in transport sector caused by COVID-19 have notable impact on economies. Economic modelling is a power tool to estimate the impact of certain shocks and evaluate the impact on other industries, regional development, and development, for example, in rural areas, etc. The research applies input-output model with additional regional modelling block using bottom-up approach. In the research two scenarios were elaborated - the first scenario that reflects the most dramatic negative shock in transport sector regarding air transport, and the second scenario that reflects the most positive sideeffect or shock in transport sector regarding postal and courier services that face unexpected demand increase due to face-to-face shopping limitations and online shopping booming that demands delivery.
The findings demonstrate that service industries are more affected by both collapse in air transport (first scenario) and booming postal and courier services (second scenario), agriculture, manufacturing and energy sector are significantly less affected.

The results of regional modelling according to NUTS 3 level argue that the capital city region (Riga region) and suburbs (Pieriga region) are affected more than other regions in both modelling scenarios. The findings confirm that the urban areas due to higher economic activity and larger service sector are more affected to shocks both negative and positive that transport sector encounters. The rural areas are relatively less negatively affected during the crisis, but at the same time, during the economic recovery or some short-term economic boom (for example, in the post-COVID era) it may lead to weaker economic activity and the rural areas will continue to lag behind urban areas. This is an issue that the regional policy and economic policy makers are encouraged to take into account in order to ensure a more balanced regional economic development.

\section{References}

Abel, G.J., \& Gietel-Basten, S. (2020). International remittance flows and the economic and social consequences of COVID-19. Environment and Planning A, 52(8), 1480-1482. DOI: 10.1177/0308518X20931111.

Arbolino, R., \& Caro, P.D. (2020). Can the EU funds promote regional resilience at time of Covid-19? Insights from the Great Recession ${ }^{1}$. Journal of Policy Modeling. DOI: 10.1016/j.jpolmod.2020.10.001.

Auzina-Emsina, A., \& Ozolina, V. (2019). Modelling impact of Urban-rural income convergence in the EU. Research for Rural Development, 2, 210-216. DOI: 10.22616/rrd.25.2019.071.

Bonet-Morón, J., Ricciulli-Marín, D., Pérez-Valbuena, G.J., Galvis-Aponte, L.A., Haddad, E.A., Araújo, I.F., \& Perobelli, F.S. (2020). Regional economic impact of COVID-19 in Colombia: An input-output approach. Regional Science Policy and Practice, 12(6), 1123-1150. DOI: 10.1111/rsp3.12320.

Collier, P., \& Mayer, C. (2020). Reforming the UK financial system to promote regional development in postCOVID Britain. Oxford Review of Economic Policy, 36, S270-S280. DOI: 10.1093/oxrep/graa028.

Couto, G., Castanho, R.A., Pimentel, P., Carvalho, C., Sousa, Á., \& Santos, C. (2020). The impacts of COVID-19 crisis over the tourism expectations of the Azores Archipelago residents. Sustainability (Switzerland), 12(18). DOI: $10.3390 / \mathrm{su} 12187612$.

Eurostat. (2018). Urban-rural typology. Retrieved October 12, 2020, from https://ec.europa.eu/eurostat/ statistics-explained/index.php?title=Glossary:Urban-rural_typology.

Eurostat. (2020). Impact of COVID-19 on air passenger transport in Q2 2020. Retrieved October 20, 2020, from https://ec.europa.eu/eurostat/web/products-eurostat-news/-/DDN-20201015-2.

Giammetti, R., Papi, L., Teobaldelli, D., \& Ticchi, D. (2020). The Italian value chain in the pandemic: the inputoutput impact of Covid-19 lockdown. Journal of Industrial and Business Economics, 47(3), $483-497$. DOI: $10.1007 / \mathrm{s} 40812-020-00164-9$.

Gray, R.S. (2020). Agriculture, transportation, and the COVID-19 crisis. Canadian Journal of Agricultural Economics, 68(2), 239-243. DOI: 10.1111/cjag.12235.

Kim, K. (2021). Impacts of COVID-19 on transportation: Summary and synthesis of interdisciplinary research. Transportation Research Interdisciplinary Perspectives, 9. DOI: 10.1016/j.trip.2021.100305.

Lenzen, M., Li, M., Malik, A., Pomponi, F., Sun, Y.-Y., Wiedmann, T., ... Yousefzadeh, M. (2020). Global socio-economic losses and environmental gains from the coronavirus pandemic. PLoS ONE, 15(7 July). DOI: 10.1371/journal.pone.0235654.

Monmousseau, P., Marzuoli, A., Feron, E., \& Delahaye, D. (2020). Impact of Covid-19 on passengers and airlines from passenger measurements: Managing customer satisfaction while putting the US Air Transportation System to sleep. Transportation Research Interdisciplinary Perspectives, 7. DOI: 10.1016/j.trip.2020.100179. 
Renaud, L. (2020). Reconsidering global mobility-distancing from mass cruise tourism in the aftermath of COVID-19. Tourism Geographies, 22(3), 679-689. DOI: 10.1080/14616688.2020.1762116.

Santamaria, C., Sermi, F., Spyratos, S., Iacus, S. M., Annunziato, A., Tarchi, D., \& Vespe, M. (2020). Measuring the impact of COVID-19 confinement measures on human mobility using mobile positioning data. A European regional analysis. Safety Science, 132. DOI: 10.1016/j.ssci.2020.104925.

Sobieralski, J.B. (2020). COVID-19 and airline employment: Insights from historical uncertainty shocks to the industry. Transportation Research Interdisciplinary Perspectives, 5, 100123. DOI: 10.1016/j. trip.2020.100123.

Sun, X., Wandelt, S., \& Zhang, A. (2020). How did COVID-19 impact air transportation? A first peek through the lens of complex networks. Journal of Air Transport Management, 89, 101928. DOI: 10.1016/j. jairtraman.2020.101928.

Tirachini, A., \& Cats, O. (2020). COVID-19 and public transportation: Current assessment, prospects, and research needs. Journal of Public Transportation, 22(1), 1-34. DOI: 10.5038/2375-0901.22.1.1.

Wen, L., Sheng, M., \& Sharp, B. (2021). The impact of COVID-19 on changes in community mobility and variation in transport modes. New Zealand Economic Papers. DOI: 10.1080/00779954.2020.1870536.

Wielechowski, M., Czech, K., \& Grzęda, Ł. (2020). Decline in mobility: Public transport in Poland in the time of the COVID-19 pandemic. Economies, 8(4). DOI: 10.3390/ECONOMIES8040078. 